\title{
LA MIGRACIÓN INTERNACIONAL EN EL ACTUAL PERIODO DE GLOBALIZACIÓN DEL SISTEMA MUNDO-MODERNO/COLONIAL
}

\author{
CÉSAR GERMANÁ
}

Universidad Nacional Mayor de San Marcos. Lima (Perú).

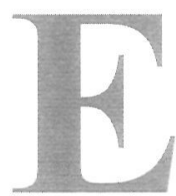

\section{RESUMEN}

n el presente trabajo quisiera explorar algunos de los problemas del fenómeno de la migración internacional planteados en el mundo contemporáneo. En primer lugar, examino las características específicas de la migración internacional, buscando diferenciarla de lo ocurrido en periodos anteriores; para ello tengo como punto de partida las influyentes propuestas centradas en el concepto de sistema-mundo moderno de Immanuel Wallerstein y en el concepto de colonialidad del poder de Aníbal Quijano. En segundo lugar, analizo la construcción de la imagen del inmigrante y del emigrante en el imaginario dominante en los países ricos y en los países pobres. Finalmente, en tercer lugar, discuto los conflictos que se están generando con la inclusión de los migrantes en el espacio social transnacional.

Palabras clave: Migración internacional, colonialidad, sistemamundo.

\section{LA ESPECIFICIDAD DEL FENÓMENO MIGRATORIO EN LA ÉPOCA ACTUAL}

El fenómeno migratorio se ha intensificado en los últimos cincuenta años. Según el informe preparado por la División de Población del Secretariado de las Naciones Unidas, "en 2000, había 175 millones de migrantes ${ }^{2}$ en el mundo, esto es, uno de cada 35 personas en el mundo era un migrante internacional. Ese total representaba un incremento

1 Este texto es parte de la fundamentación del proyecto de investigación sobre el perfil del potencial migrante profesional peruano que hemos iniciado en la Universidad Nacional Mayor de San Marcos.

2 El migrante internacional es la persona que vive en un país diferente al que ha nacido. 
de 76 millones con respecto a 1960. En comparación, la población del mundo se duplicó de 3 mil millones en 1960 a 6 mil millones en 2000 . En consecuencia, los migrantes internacionales representaban el 2.5 por ciento de la población mundial en 1960 y el 2.9 por ciento en $2000^{\prime \prime} 3$. Si se hubiese mantenido la tasa de crecimiento de la migración internacional del periodo 1990-2000, la población migrante en 2005 alcanzaría entre 185 y 192 millones.

Sin embargo, la migración internacional no es un fenómeno nuevo. En los últimos quinientos años ha habido un importante flujo de población migrante. La primera ola fue la de una migración colonizadora. Entre los siglos XVI y XVIII, se produce una importante salida de población europea que va a colonizar América; pero estos migrantes no aprendieron el náhuatl o el quechua; más bien ellos impusieron a los nativos el castellano o el portugués. Pero no solamente fue una colonización lingüística, también colonizaron el imaginario y las maneras de pensar y de sentir de la población amerindia. En este sentido, a diferencia de lo que ocurre con los actuales migrantes que deben integrarse y someterse a la cultura de los países a donde llegan, los conquistadores no solamente no se integraron a las culturas de Anahuac o del Tawantinsuyo sino que les impusieron los usos y costumbres de los europeos.

La segunda ola migratoria se produce entre la segunda mitad del siglo XIX y los primeros decenios del siglo XX. Esta fue una migración civilizadora. En el proceso de constitución de los Estados nacionales de América, las élites dominantes buscaban el progreso en la civilización europea y para lograrlo desarrollan políticas tendientes a favorecer la inmigración de la población "blanca"; querían poblar a los países americanos con los representantes de la modernidad. En ese periodo, millones de europeos cruzaron el Atlántico para establecerse en América y civilizar a las naciones "bárbaras". Así, se va imponiendo en el imaginario colonial lo que a partir de fines del siglo XIX se denominará "América Latina".

La migración internacional de la segunda mitad del siglo XX será muy diferente a la de los periodos anteriores, no solamente porque el desplazamiento demográfico va a seguir la ruta que lleva de los países pobres a los países ricos, sino, sobre todo, porque esta población nómada se irá constituyendo en un espacio social transnacional ${ }^{4}$. En el periodo de transición del sistema-mundo moderno/colonial que estamos viviendo, donde las estructuras del Estado-nación se están ero-

3 International Organization for Migration (IOM), World Migration 2005: Costs and Benefits of International Migration, Switzerland, IOM, 2005, p. 379.

4 Concepto propuesto por Ulrich Beck en ¿Qué es la globalización? Falacias del globalismo, respuestas a la globalización, Barcelona, Paidós, 1998. 
sionando aceleradamente, la migración internacional ya no puede ser vista desde la perspectiva de una fase de salida (la partida, el viaje y los lugares intermedios) o de una fase de entrada (la llegada y la conflictiva y nunca concluida integración); ahora se trata de mirar la migración desde una óptica diferente donde el migrante se establece en espacios sociales donde "enlazan y modifican los lugares de procedencia y los de destino"s.

Pero, además, como lo ha señalado Immanuel Wallerstein, la migración internacional, en el presente periodo de transición, se manifiesta como una de las formas más explosivas del proceso de desorganización y crisis del sistema-mundo moderno/colonial porque se trata de una erupción que ha cruzado "un umbral de importancia en la vida del sistema, y ha comprometido las fuerzas centrífugas inherentes a la crisis estructural, al periodo de bifurcación" $"$. Este papel de la migración internacional en la crisis del sistema-mundo moderno/colonial está vinculado a la creciente identidad étnica que van asumiendo las poblaciones migrantes en los países centrales por el hecho de ser segregados y excluidos en todos los ámbitos de la vida social por una población rica, con poder y sobre todo autodefinida como "blanca". En estas circunstancias, los enfrentamientos con los grupos de radicales nacionalistas y racistas, que buscan una imaginaria limpieza étnica, llevarán a que "todos los países [ricos] tendrán su propio polvorín [y] cualquier brote de hostilidades podría extenderse fácilmente más allá de sus fronteras, como un incendio forestal sin control"'?.

\section{LA CRISIS DEL SISTEMA-MUNDO MODERNO/COLONIAL}

La noción de sistema-mundo moderno8 desarrollada por Immanuel Wallerstein constituye el punto de partida de nuestro estudio sobre la migración internacional. El sistema mundo-moderno surgió con la con-

5 Ibíd., p. 53.

6 Immanuel Wallerstein, Utopistica o las opciones históricas del siglo XXI, México, Siglo XXI editores, 1998 , p. 58 .

7 Ibíd., p. 62.

8 Para 1. Wallerstein, "un sistema mundial es un sistema social, un sistema que posee límites, estructuras, grupos, miembros, reglas de legitimación, y coherencia. Su vida resulta de las fuerzas conflictivas que lo mantienen unido por tensión y lo desgarran en la medida en que cada de los grupos busca eternamente remodelarlo para su beneficio. Tiene las características de un organismo, en cuanto a que tiene un tiempo de vida durante el cual sus características cambian en algunos aspectos y permanecen estables en otros". 1 . Wallerstein, El moderno sistema mundial. La agricultura capitalista y los origenes de la economia-mundo europea en el siglo XVI, México, Siglo XXI editores, 1979, p. 489. Una presentación de los principios que ordena el análisis de los sistemas-mundo se encuentra en "EI análisis de los sistema-mundo", en: I. Wallerstein, Capitalismo histórico y movimientos antisistémicos. Un análisis de los sistemas-mundo, Madrid, Akal, 2004. 
quista de América en el siglo XVI y se expandió y consolidó en los siglos posteriores hasta convertirse en un "sistema social total", articulando un centro dominante y una periferia dominada. La economíamundo capitalista surgió en el siglo XV y "debido a su lógica interna, esta economía-mundo capitalista se extendió más tarde hasta abarcar todo el globo, y en ese proceso absorbió a todos los minisistemas e imperios-mundo existentes. Así, hacia finales del siglo XIX existía por primera vez en la historia un único sistema histórico; nos encontramos todavía en esa situación"9. Este sistema histórico, que constituye un espacio-tiempo específico, articula, en primer lugar, una estructura económica organizada alrededor de la incesante acumulación de capital en un mercado mundial; en segundo lugar, una estructura política basada en Estados-nación soberanos jurídicamente pero interdependientes; $y$, en tercer lugar, una estructura cultural -la geocultura- que lo legitima y le da coherencia. Como todo sistema-mundo, el sistema histórico moderno, después de un largo desarrollo, ha alcanzado un punto de bifurcación en la medida de que se ha apartado del equilibrio "y ha entrado en una crisis terminal y dentro de cincuenta años es poco probable que exista"10. En este sentido, nos encontramos en un periodo de transición, donde las fuerzas centrífugas están generando desorden y desorganización en todos los órdenes del sistema mundo-moderno colonial.

Para una compresión cabal del sistema-mundo moderno se necesita incorporar la noción de colonialidad del poder propuesta por Aníbal Quijano. Para Quijano, "la colonialidad es uno de los elementos constitutivos y específicos del patrón mundial de poder capitalista. Se funda en la imposición de una clasificación racial/étnica de la población del mundo como piedra angular de dicho patrón de poder y opera en cada uno de los planos, ámbitos y dimensiones, materiales y subjetivas, de la existencia social cotidiana y a escala societal. Se origina y mundializa a partir de América"11. Por esta razón, la propuesta de I. Wallerstein de analizar el sistema-mundo moderno sería incompleta si no se considera

9 1. Wallerstein, Capitalismo histórico y movimientos antisistémicos. Un análisis de los sistemas-mundo, op. cit., 143.

10 1. Wallerstein, Conocer el mundo, saber el mundo: el fin de lo aprendido. Una ciencia social para el siglo $X X I$, México, Siglo XXI editores, 2001, p. 5.

11 A. Quijano, "Colonialidad del poder y clasificación social", en Journal of Word-Systems Research, Vol. XI, No. 2, Summer/Fall 2000, p. 342. A. Quijano ha desarrollado el concepto de colonialidad del poder en diversos textos. Entre los más significativos se encuentran: "Colonialidad y Modernidad/Racionalidad" en Perú Indigena (Lima), Vol. 13, No. 29, 1991; en colaboración con I. Wallerstein, "Americanity as a Concepto or the Americas in the Modern Word System" en International Journal of Social Sciences (Paris), No. 134, Nov. 1992; "Colonialidad del poder, eurocentrismo y América Latina", en: E. Lander (Compilador), La colonialidad del saber: eurocentrismo y ciencias sociales. Perspectivas latinoamericanas, Buenos Aires, CLACSO, 2000; "Colonialidad del poder: cultura y conocimiento en América Latina", en: W. Mignolo (Compilador), Capitalismo y geopolítica del conocimiento: el eurocentrismo y la filosofía de la liberación en el debate intelectual contemporáneo, Buenos Aires, Ediciones del Signo, 2001. W. Mignolo discute el concepto de colonialidad del poder en "Un paradigma otro": colonialidad global, pensamiento fronterizo y 
la otra cara de ese patrón de dominación; esto es, la colonialidad, que es su elemento constitutivo. De esta manera, en sentido estricto, podemos hablar del sistema-mundo moderno/colonial.

En la conceptualización de la colonialidad, para A. Quijano el poder es considerado como "un espacio y una malla de relaciones sociales de explotación/dominación/conflicto" que se articulan en cuatro ámbitos sociales: trabajo, género/sexualidad, autoridad e intersubjetividad ${ }^{12}$. Cuando el patrón de poder es atravesado por la idea de "raza" -esto es, las diferencias fenotípicas entre conquistadores y conquistados que dio lugar a nuevas formas de identificación como "indio", "negro", "mestizo", "blanco"13 - podemos hablar de la colonialidad. "La "racialización' de las relaciones de poder entre las nuevas identidades sociales y geoculturales, fue el sustento y la referencia legitimatoria fundamental del carácter eurocentrado del patrón de poder, material e intersubjetivo"14.

Con la colonialidad del poder se estableció, en consecuencia, "una nueva intersubjetividad mundial" donde Europa hegemonizó el imaginario, la cultura y el conocimiento y su manera de producirlo. La forma que adquirió esa perspectiva cognoscitiva ha sido el eurocentrismo que colonizó el mundo de las relaciones intersubjetivas del sistema-mundo moderno. Tres mitos han sido los principales constituyentes del eurocentrismo: una concepción de la evolución de la humanidad que tiene a Europa como punto de llegada; una concepción limitada del universalismo, donde los conocimientos producidos en Europa son verdades válidas para todo tiempo y lugar; y una concepción del progreso como un futuro necesario, determinado e ineludible ${ }^{15}$.

El concepto de colonialidad del poder es de fundamental importancia para comprender la migración de la época actual porque ofrece un marco de referencia donde la jerarquía étnico/racial, tanto en los países centrales como en los periféricos, ordena las relaciones sociales. Así se puede explicar cómo los inmigrantes en las metrópolis van a definir sus identidades sobre una base colonial. Tanto las prácticas sociales como el imaginario de los migrantes están atravesados por la colonialidad del

cosmopolitismo crítico", prefacio a la edición castellana de Historias locales/diseños globales. Colonialidad, conocimientos subalternos y pensamiento fronterizo, Madrid, Akal, 2003.

12 A. Quijano, "Colonialidad del poder y clasificación social", op. cit., p. 345.

13 Para una discusión sobre la idea de raza y del racismo contemporáneo, véanse: I. Wallerstein y E. Bolivar, Raza, nación y clase, Madrid, IEPALA, 1991 y de A. Quijano, "Raza", "etnia", "nación” en Mariátegui: cuestiones abiertas", en R. Forgues (ed.), José Carlos Mariátegui y Europa. La otra cara del descubrimiento, Lima, Amauta, 1992.

14 A. Quijano, "Colonialidad del poder y clasificación social", op. cit., p. 374.

15 Una presentación de los principales problemas en el debate del eurocentrismo se encuentra en: I. Wallerstein, "El eurocentrismo y sus avatares: los dilemas de las ciencias sociales", en Capitalismo histórico y movimientos antisistémicos. Un análisis de sistemas-mundo, op. cit. 
poder. La migración actual es por lo tanto un buen indicador de la continuidad de los procesos sociales marcados por jerarquías étnico/raciales que se establecieron durante la conquista europea de América.

Es la dinámica de este sistema histórico lo que nos permite comprender la lógica del proceso migratorio en los periodos anteriores y en la actualidad. Tanto las migraciones del periodo de la expansión del sistema colonial como las de la segunda mitad del siglo XIX y de los inicios del siglo XX estuvieron vinculadas a la necesidad de desplazar la fuerza de trabajo de los países centrales a los periféricos. Las características de las migraciones de la época actual están determinadas por el periodo de crisis y transición por el que atraviesa el mundo contemporáneo, al que se le denomina globalización.

Para Wallerstein, la crisis es la característica actual del sistema-mundo capitalista, el que se encuentra lejos del equilibrio y comienza a bifurcarse hacia otro u otros sistema-mundos; en esta medida se puede definir como un periodo de transición. En la base de esta crisis del funcionamiento del sistema-mundo capitalista se encuentran dos contradicciones fundamentales: la primera está dada por dos factores que se mueven en direcciones opuestas, "mientras que la maximización del beneficio a corto plazo requiere minimizar la cantidad de excedente que consume inmediatamente la mayoría, a largo plazo la producción continua de excedente requiere una demanda de masas que sólo puede crear redistribuyendo el excedente producido"; y la segunda, que crece el coste de "cooptación" y donde las ventajas son cada vez menores, pues "en la medida en que los detentadores de privilegios tratar de cooptar al movimiento de oposición concediéndole una pequeña participación en los privilegios, sin duda eliminan opositores a corto plazo, pero también encarecen la cotización del movimiento de oposición que se genere en la siguiente crisis de la economía-mundo"16. Se podría señalar, en consecuencia, que el actual periodo de crisis y reestructuración está marcado por la agudización de las divisiones en la estructura de poder global y por la intensificación de la desigualdad y de la exclusión social. Globalización económica y exclusión social son las dos caras de la época actual.

16 I. Wallerstein, "El ascenso y futura decadencia del sistema-mundo capitalista: conceptos para un análisis comparativo", en Capitalismo histórico y movimientos antisistémicos. Un análisis de sistemas-mundo, op. cit., pp. 113-114. 


\section{LA CONSTRUCCIÓN SOCIAL DEL MIGRANTE EN EL PE- RIODO DE TRANSICIÓN}

El imaginario del mundo-moderno/colonial ha estado dominado por la colonialidad del poder. Siguiendo la propuesta de Walter Mignolo, considero el imaginario como el modo por el cual una determinada cultura se percibe a si misma y al mundo en el que se encuentra inserta. "El imaginario del mundo moderno/colonial -señala- es su propia descripción, los modos en los que se describe a sí mismo por medio del discurso del Estado, de los intelectuales y de los académicos"17. Es en este imaginario donde se ha construido la figura del migrante, tanto entre los habitantes de los países ricos como entre los habitantes de los países pobres. En el actual periodo de transición, también el imaginario de la cultura del mundo moderno/colonial está en crisis. Y se está rehaciendo de manera contradictoria y ambigua. Por esta razón, la imagen del migrante no está totalmente delimitada y aparece constituida por inseguridades, odios, temores y frustraciones.

La construcción social del migrante tendrá una consecuencia práctica muy grande, como lo establece el "teorema de Thomas": "lo que los hombres definen como real es real en sus consecuencias". Así, tan pronto como se forja una imagen del inmigrante se actúa en consecuencia, lo que lleva a determinadas prácticas socialmente aceptadas. Podemos señalar, como propone Enrique Santamaría para el caso de inmigrantes a Europa, que "la emergencia de la 'inmigración no comunitaria' no puede ser imaginada más que a partir de ese proceso de construcción europea que la adjetiva (negativamente) y que genera una nueva línea de demarcación social, una nueva frontera simbólica que instituye nuevas categorías sociopolíticas $y$, por ende, nuevas comunidades imaginadas"18. Desde esta perspectiva, me gustaría explorar algunos de los elementos constitutivos de la figura del migrante en la época actual.

La imagen del migrante en los países ricos se define socialmente alrededor de jerarquías de naturaleza étnico/racial. Así, el inmigrante es el "no blanco", aunque no todos tienen ese fenotipo. Se reproduce, cinco siglos después, la racialización de las relaciones de poder donde los inmigrantes que provienen de diferentes tradiciones culturales son unificados como "no blancos". De esta manera se les puede reconocer físicamente y considerarlos separados, como diferentes. Por esta razón, la segunda, la tercera y hasta la cuarta generación de los descendien-

17 W. Mignolo, Historias locales/diseños globales. Colonialidad, conocimientos subalternaos y pensamiento fronterizo, Madrid, Akal, 2003, p. 83.

18 E. Santamaría, "Inmigración y barbarie. La construcción social y política del inmigrante como amenaza", en Papers 66, 2002, p. 63. 
tes de los inmigrantes propiamente dichos son considerados migrantes. Aparece, como consecuencia de la colonialidad del poder, la figura del inmigrante colonial, esto es, del inmigrante que en la sociedad adonde llega es clasificado con los criterios coloniales/raciales por los autodenominados "blancos".

Además, los inmigrantes "no blancos" son percibidos como los pobres; los que por su situación económica precaria en sus países de origen tienen que migrar. Al llegar a la sociedad rica, al inmigrante se le considera una competencia desleal en el mercado de trabajo, pues va a aceptar cualquier empleo e ingresos mínimos con lo cual presionan para hacer descender los salarios. Así, el mercado de trabajo se racializa, pues determinadas ocupaciones las ocupan los "no blancos" y tienen los empleos peor remunerados.

En el imaginario dominante sobre el inmigrante, también se le considera como a un extraño que llega para aprovecharse de los beneficios del Estado asistencial. Particularmente se les considera como personas que no pueden tener los derechos políticos y sociales de los verdaderos ciudadanos que son los "blancos". Así, se les escamotea los derechos a la educación, a la salud y a la seguridad social; o en todo caso, se les considera como ciudadanos de segunda clase.

Pero la nota dominante en el imaginario sobre el inmigrante se encuentra la imagen del que crea los "problemas sociales". Se les hace responsable de crímenes que van desde el robo hasta el narcotráfico y la prostitución. Los inmigrantes emergen como los nuevos bárbaros que llevan consigo la delincuencia y la corrupción. Quizás el mejor ejemplo de esta sensación está dado por las pandillas. Las bandas juveniles que atemorizan a la población de las grandes ciudades se convierten en la encarnación de todos los males de la inmigración ${ }^{19}$.

Más aún, a los inmigrantes se les imagina como la fuerza social que está poniendo fin a la identidad de las sociedades dominantes, pues los inmigrantes no logran "integrarse" y mantienen su lengua y sus costumbres. Este el tema central que desarrolla Samuel Huntington cuando señala que uno de los desafíos mayores a la identidad nacional estadounidense está dada por la oleada inmigratoria iniciada en la década de la década de 1960 que llevó a los Estados Unidos a millones de latinoamericanos y asiáticos, donde "la cultura y los valores de sus países de origen difieren sustancialmente, en muchos casos, de los habituales en Estados Unidos. Para estos inmigrantes resulta mucho más fácil

19 Las investigaciones reunidas en el libro editado por Luca Queirolo Palmas y Andrea T. Torre, Il fantasma delle bande. Genova e i latinos (Genova, Fratelli Frilli Editori, 2005) constituyen una muestra del imaginario predominante en la sociedad europea sobre los inmigrantes. 
mantener el contacto con sus países de origen y seguir perteneciendo culturalmente a los mismos"20. También es ilustrativo el análisis de E. Santamaría de la "inmigración no comunitaria" como "problema social". Sostiene que "el discurso sobre la 'inmigración no comunitaria' insiste en aprehender la cuestión en términos de una 'avalancha' imparable que no sólo es causa de 'problemas sociales', sino que también es en sí misma un grave problema social y cultural, pues los migrantes, con sus diferencias culturales, con los problemas que tienen y generan, amenazan la cohesión social, la seguridad económica, la homogeneidad cultural e incluso la estabilidad política $[\ldots]^{\prime 221}$.

De otro lado, en las sociedades periféricas, a diferencia de las sociedades ricas, donde a los migrantes no se les tiene mucho aprecio, existe una imagen muy positiva de emigrante. En una encuesta realizada en Lima, en el mes de mayo de 2005, señalaba que el 77 por ciento de los entrevistados respondían que si pudieran se irían del país ${ }^{22}$. Este alto porcentaje de potenciales migrantes revela que no es la falta de empleo lo que los empujaría a la emigración sino la representación de un futuro promisorio en el largo plazo en las metrópolis ricas ${ }^{23}$. Este estado de ánimo refleja que el emigrante no es mal visto socialmente sino que más bien es alentado y reconocido. Cuando, según el Ministerio de Relaciones Exteriores del Perú, 1,733,439 peruanos residen en el extranjero formalmente (al que habría que agregar el amplio sector de peruanos que migran de manera ilegal $)^{24}$, la migración hace parte de la vida cotidiana de gran parte de las familias peruanas, particularmente urbanas.

En esas circunstancias, el emigrante aparece como potencialmente exitoso, capaz de mejorar económicamente y de ofrecer una existencia mejor a su familia. La migración es parte del mito del progreso; se puede tener una ocupación con una remuneración importante, se puede cambiar el estatus social y se puede incorporar a la sociedad blanca y rica. Es el "sueño americano" o el "sueño europeo", pues en Europa o en Estados Unidos se puede participar de la sociedad del consumo, sin las limitaciones que da la pobreza del país de origen. El consumismo,

20 S. Huntington, ¿Quiénes somos? Los desafios a la identidad nacional estadounidense, Barcelona, Paidós, 2004 , p. 43.

21 E. Santamaría, art. cit., pp. 68-69.

22 El Comercio (Lima), 15 de mayo 2005, p. a8.

23 El Pew Hispanic Center en un sondeo de migrantes mexicanos indocumentados, reveló que la mayoría contaba con empleo antes de emigrar a Estados Unidos: sólo cinco por ciento estaban desempleados antes de salir de su pais. Véase el informe en: http://pewhispanic.org/reports/report.php?ReportID=58.

24 Los datos del Ministerio de Relaciones Exteriores del Perú fueron publicados por el diario El Comercio (Lima) el 20 de marzo de 2005. Para ese momento, se calculaba que la población del Perú era de 27 millones 500 mil habitantes 
impuesto por la ideología neoliberal, se convierte en la meta valorada del emigrante.

Los mecanismos de la colonialidad del poder funcionan para dar fundamento a esta imagen del migrante. La cultura impuesta por los países centrales sobre las sociedades colonizadas ha llevado a considerar como propias los conocimientos, los valores y las maneras de ver el mundo y de verse a sí mismo que tienen de los europeos. Esta visión eurocéntrica ${ }^{25}$ es la que llevó a la negación y a la ruptura de las poblaciones nativas con su propio mundo cultural, y en la actualidad se reproduce con la desesperada búsqueda, por parte de los migrantes, por alcanzar el mundo que los colonizó.

Además, se debe tener en cuenta la importancia de los migrantes por significativas sumas de dinero que envían a sus familiares. Según el Fondo Multilateral de Inversiones (FOMIN) del Banco Interamericano de Desarrollo las remesas de los migrantes hacia América Latina alcanzó la suma de 45, 800 millones de dólares el año 2004. En el caso del Perú, las remesas enviadas al Perú por emigrados en América del Norte, Europa, Japón y otros países latinoamericanos en el año 2004 fueron de 1,360 millones de dólares y sed calcula que superarán los 2,495 para el año $2005^{26}$. En estas condiciones, los emigrantes tienen una alta valoración en imaginario social.

\section{CONCLUSIÓN. LA CONFLICTIVA INCORPORACIÓN DEL MIGRANTE EN EL ESPACIO SOCIAL TRANSNACIONAL}

Como hemos señalado al inicio de este texto, una de las características centrales del periodo de transición es la constitución de un espacio social transnacional, que se ha ido consolidando en la media que las

25 Sobre el eurocentrismo existe un amplio debate en las ciencias sociales que cstá relacionado con su presencia en las diferentes esferas de la vida social. "Es una hidra multicéfala que tiene muchas encarnaciones" (l. Wallerstein, Capitalismo histórico y movimientos antisistémicos. Un análisis de sistemas-mundo, op. cit., $\mathrm{p}$ 328). Aníbal Quijano lo considera como la forma específica que asume el saber que se desarrolla cn Europa a partir del siglo XVII y se impone como la perspectiva hegemónica de conocimiento en el sistema-mundo moderno/colonial. "No se trata - precisa Aníbal Quijano-, en consecuencia, de una categoría que implica a toda la historia cognoscitiva en toda Europa, ni en Europa Occidental en particular. En otros términos, no se refiere a todos los modos de conocer de todos los europeos y en todas las épocas, sino a una específica racionalidad o perspectiva de conocimiento que se hace mundialmente hegemónica colonizando y sobreponiéndose a todas las demás, previas o diferentes, y a sus respectivos saberes concretos, tanto en Europa como en el resto del mundo" (A. Quijano, "Colonialidad del poder, eurocentrismo y América Latina", en: E. Lander (Compilador), La colonialidad del saber: eurocentrismo y ciencias sociales. Perspectivas latinoamericanas, Buenos Aires, CLACSO, 2000, p. 2 [9). Desde esta perspectiva, el eurocentrismo no solo puede verse como una lorma de parroquianismo - esto es, que sus categorías, teorías e hipótesis surgicron para dar respuesta a los problemas europeos-, sino que su núcleo central está dado por el colonialismo, pues la perspectiva eurocéntrica colonizó el universo de las relaciones intersubjetivas del sistema-mundo moderno/colonial.

$26 \mathrm{http}: / / \mathrm{www} . \mathrm{iadb}, \mathrm{rg} / \mathrm{mil} / \mathrm{remitlances} /$ 
estructuras del Estado-nación se han ido erosionando. La mundialización arrastra la desaparición gradual de los principios, modos de organización y de valorización de los recursos materiales e inmateriales de las sociedades nacionales: Estado nacional, moneda nacional, derecho nacional, soberanía nacional, educación nacional, cultura nacional. Todas estas instituciones que surgieron con la modernidad tienden a mundializarse. La creación de un "espacio social transnacional" ha sido enfatizada por U. Beck: "En general, se puede afirmar que se ha venido abajo una premisa esencial de la primera modernidad, a saber la idea de vivir y actuar en espacios cerrados y recíprocamente delimitados de los Estados nacionales y de sus respectivas sociedades nacionales. Globalización significa la perceptible pérdida de fronteras del quehacer cotidiano en las distintas dimensiones de la economía, la información, la ecología, la técnica, los conflictos transculturales y la sociedad civil $\mathrm{y}$, relacionada bastante con todo eso, una cosa que es al mismo tiempo familiar e inasible - difícilmente captable- que modifica a todas luces con perceptible violencia la vida cotidiana y que fuerza a todos a adaptarse y responder ${ }^{27}$.

Los migrantes son los habitantes por antonomasia de este espacio social transnacional. Están, a la vez, aquí y allá, en la sociedad de origen y en la sociedad de llegada. Los migrantes no logran integrarse totalmente a la sociedad a la que arriban; pero tampoco rompen completamente con la sociedad de la que partieron. Son los pobladores de un nuevo mundo que se irá consolidando en las próximas décadas.

El reconocimiento de este hecho se encuentra formalmente expresado en la aceptación de la doble nacionalidad que están concediendo muchos Estados, como lo ha establecido la recientemente promulgada Constitución de Chile. Pero más importante que este hecho legal, es la presencia permanente del mundo cultural de los migrantes tanto en la sociedad de origen como en la de llegada. Un buen ejemplo de esta presencia de las tradiciones culturales que se reafirman y se reproducen permanentemente se encuentra en el estudio de Javier Ávila Molero sobre la migración de los campesinos andinos hacia Lima y los Estados Unidos $^{28}$.

La presencia de los migrantes en el espacio social transnacional se encuentra afirmado por la abierta o silenciosa exclusión de la que son objeto por parte de las sociedades a donde llegan. Esta discriminación se cristaliza en la forma de racismo. Inclusive muchas veces el racismo tiene como sustituto la categoría de inmigrante. El racismo funciona

27 U. Beck, ¿Qué es la globalización? Falacias del globalismo y respuestas a la globalización, op. cit., p. 42.

28 Javier Ávila, Andes (trans)nacionales. Globalización y muevos sujetos migrantes, Tesis de Maestria en Antropología, Escuela de Post Grado de la Universidad Católica de Perú. 
como mecanismo para adecuar la oferta y la demanda al mercado de trabajo. En este sentido, se puede hablar de la "etnificación" de la fuerza del trabajo ${ }^{29}$ para referirse a la jerarquía de ocupaciones y remuneraciones que tiene como fundamento criterios supuestamente raciales. Pero, además, el racismo permite justificar la desigualdad, la diferencia entre los derechos de los nativos y de los migrantes.

Ante el rechazo y la segregación, el inmigrante tiende a desarrollar una estrategia tendiente a lograr un punto de referencia para su supervivencia social en un medio hostil. Es estas condiciones, se irán acentuando los rasgos culturales que provienen de sus tradiciones nacionales y desarrollarán una identidad étnica en el complejo laberinto de la colonialidad. La identidad no es una sustancia, algo idéntico en sí mismo de manera permanente; la identidad se afirma en el marco de las relaciones establecidas entre nativos e inmigrantes. Esta identidad se va construyendo constantemente, tanto desde la perspectiva del que busca un reconocimiento como del que debe reconocerlo. El enfrentamiento con los sectores conservadores racistas que pretenden imponer una supuesta limpieza étnica, llevará a los inmigrantes a desarrollar un fuerte sentimiento de pertenencia a un mundo cultural diferente; a percibirse y definirse como distintos.

Este componente étnico/racial de las relaciones entre nativos e inmigrantes se encuentra en la base del imaginario que se ha ido construyendo sobre el extranjero en los países ricos. Cuando se habla del "hispano", en los Estados Unidos, o del "extracomunitario", en Europa, aparecen los prejuicios y esteriotipos forjados por varios siglos de dominación colonial. La colonialidad de las relaciones de poder en el actual periodo de crisis del sistema-mundo moderno se reproduce y se consolida con la creciente migración de importantes sectores sociales de los países pobres a los ricos.

El espacio social transnacional se está convirtiendo en un ámbito de enfrentamientos coloniales, puesto que pueblos geográfica e históricamente separados han entrado en contacto y establecen relaciones jerárquicas de naturaleza étnico/racial y desarrollan conflictos muchas veces irresolubles. Los inmigrantes latinoamericanos o africanos en Estados Unidos o Europa no son solamente migrantes; son sobre todo individuos racializados colonialmente en Europa y en USA, reproduciendo las relaciones coloniales del siglo XVI en pleno siglo XXI. 


\section{BIBLIOGRAFÍA}

ÁVILA, J.: Andes (trans)nacionales. Globalización y muevos sujetos migrantes, Tesis de Maestría en Antropología, Escuela de Post Grado de la Universidad Católica del Perú.

Banco Interamericano de Desarrollo: "Remesas a Perú llegarán a 2.495 millones de dólares este año", en http://www.iadb.org/mif/remittances/

BECK, U.: ¿Qué es la globalización? Falacias del globalismo, respuestas a la globalización. Barcelona, Paidós, 1998.

HUNTINGTON, S.: ¿Quiénes somos? Los desafios a la identidad nacional estadounidense. Barcelona, Paidós, 2004.

International Organization for Migration (IOM): World Migration 2005: Costs and Benefits of International Migration, Switzerland, IOM, 2005.

MIGNOLO, W.: Historias locales/diseños globales. Colonialidad, conocimientos subalternos y pensamiento fronterizo. Madrid, Akal, 2003.

Pew Hispanic Center, Survey of Mexican Migrants, http://pewhispanic.org/reports/report. php?ReportID=58.

QUEIROLO PALMAS, L. y TORRE, A. (eds.), Il fantasma delle bande. Genova e i latinos. Genova, Fratelli Frilli Editori, 2005.

QUIJANO, A.: "Colonialidad del poder y clasificación social", en Journal of Word-Systems Research, Vol. XI, No. 2, Summer/Fall 2000.

QUIJANO, A.: "Colonialidad del poder, eurocentrismo y América Latina”, en: E. Lander (compilador): La colonialidad del saber: eurocentrismo y ciencias sociales. Perspectivas latinoamericanas. Buenos Aires, CLACSO, 2000.

QUIJANO, A.: "Colonialidad del poder: cultura y conocimiento en América Latina", en: W. Mignolo (compilador): Capitalismo y geopolitica del conocimiento: el eurocentrismo y la filosofia de la liberación en el debate intelectual contemporáneo. Buenos Aires, Ediciones del Signo, 2001.

QUIJANO, A.: "Colonialidad y Modernidad/Racionalidad" en Perí Indigena (Lima), Vol. 13, No. 29, 1991 .

QUIJANO, A. y WALLERSTEIN, I.: "Americanity as a Concepto or the Americas in the Modern Word System" en International Journal of Social Sciences (Paris), No. 134, Nov. 1992

SANTAMARÍA, E.: "Inmigración y barbarie. La construcción social y política del inmigrante como amenaza", en Papers 66, 2002.

WALLERSTEIN, I.: Capitalismo histórico y movimientos antisistémicos. Un análisis de los sistemas-mundo. Madrid, Akal, 2004.

WALLERSTEIN, I.: "Universalismo, racismo y sexismo, tensiones ideológicas del capitalismo", en: I. Wallerstein y E. Balibar, Raza, nación y clase, Madrid, IEPALA, 1991.

WALLERSTEIN, I.: Conocer el mundo, saber el mundo: el fin de lo aprendido. Una ciencia social para el siglo XXI. México, Siglo XXI editores, 2001.

WALLERSTEIN, I.: El moderno sistema mundial. La agricultura capitalista y los origenes de la economia-mundo europea en el siglo XVI. México, Siglo XXI editores, 1979.

WALLERSTEIN, 1.: Utopística o las opciones históricas del siglo XXI. México, Siglo XXI editores, 1998 . 